\title{
Wave Impact Loads on Wave-Piercing Catamarans
}

\author{
J. Lavroff ${ }^{\text {a, }}$, M.R. Davis ${ }^{\text {a }}$, D.S. Holloway ${ }^{\text {a }}$, G.A. Thomas ${ }^{\text {b }}$, J.J. McVicar ${ }^{\text {a }}$ \\ ${ }^{\text {a }}$ School of Engineering and ICT, University of Tasmania, Sandy Bay, Tasmania, Australia.

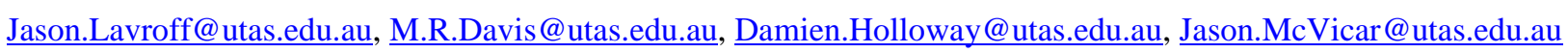 \\ ${ }^{\mathrm{b}}$ Department of Mechanical Engineering, University College London, London, United Kingdom. \\ Giles.Thomas@ucl.ac.uk
}

Keywords: Slamming, catamaran, whipping, modal frequencies, mode shape, hydroelastic segmented model, slam loads, bending moments.

\begin{abstract}
Wave slamming is investigated for the $112 \mathrm{~m} \mathrm{INCAT} \mathrm{wave-piercer} \mathrm{catamaran} \mathrm{with} \mathrm{reference} \mathrm{to} \mathrm{experimental} \mathrm{work}$ conducted at full scale, numerical computation by CFD and FEA and testing at model scale using a $2.5 \mathrm{~m}$ segmented hydro-elastic model. The segmented model was tested in regular head seas to investigate the magnitude and location of the dynamic wave slam force and slam induced hull bending moments. The model consists of rigid segments joined by elastic hinges designed to match the scaled first longitudinal modal (whipping) frequency measured at fullscale on the INCAT $112 \mathrm{~m}$ vessel. Effects of forward speed and wave encounter frequency on slamming and whipping were investigated. Scaled slam forces of up to 2150 tonnes weight (21.1 MN) were measured during model tests for a full-scale vessel with a loaded displacement of 2500 tonnes. These slams can impart impulses on the bow of up to 938 tonne weight-seconds (9.20 MNs) and strain energy of up to $3.5 \mathrm{MJ}$ into the ship structure based on scaled model test data. The impact energy is transferred primarily to the main longitudinal whipping mode, which decays with an overall structural damping ratio of 0.02 to 0.06 , this being strongly dependent on internal frictional mechanisms within the ship structure.
\end{abstract}

\section{Introduction}

The most common design of catamaran has a flat wet-deck section joining the two demi-hulls and extending to the bows of the demi-hulls. This design is effective during operation in smaller waves. However, this conventional catamaran design is prone to deck diving when operating in following seas. Deck diving causes the wet-deck to encounter the wave surface, imparting an impulsive slam load on the bow that may cause substantial structural damage (Figure 1). This occurs because conventional designs do not have substantial bow flare above the waterline 
and the forward end of the superstructure is very exposed to water entry. Designs of the semi-SWATH type with submerged bow sections are relatively soft at the bow, that is having a smaller increase of buoyant upward force on the forward hull sections with vertical displacement as the bow enters the water more deeply. As a result there is a smaller upward force as the bow enters a wave and such designs are thus more vulnerable when operating in large seas.

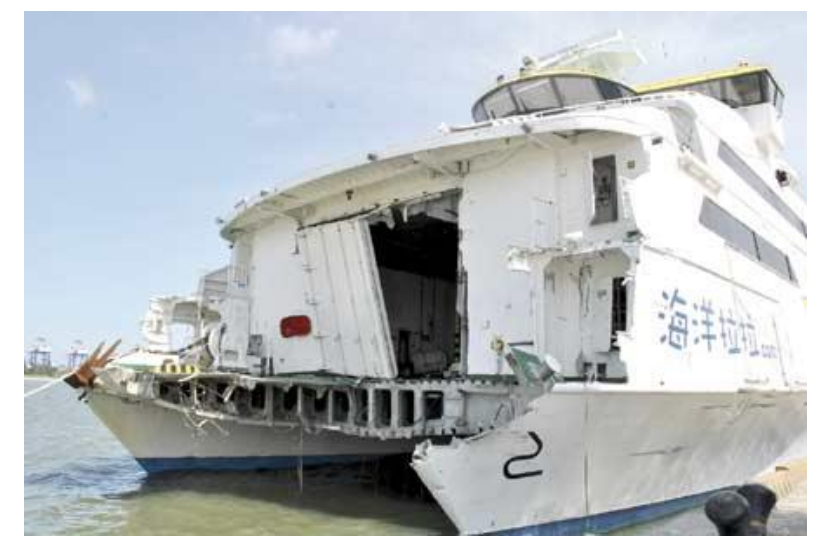

Figure 1: Damage sustained by Ocean LaLa following an extreme wet-deck slam event on $9^{\text {th }}$ August, 2010 en route from Penghu to Taichung. 311 passengers and $22 \mathrm{crew}$ were on-board the vessel when Mayday was sent at 19:04 local time 8.7 miles from port. Although there were no serious injuries recorded, 8 passengers were sent to hospital (http://www.chinapost.com.tw/taiwan/national/national-news/2010/08/10/268041/Ferry-accident.htm).

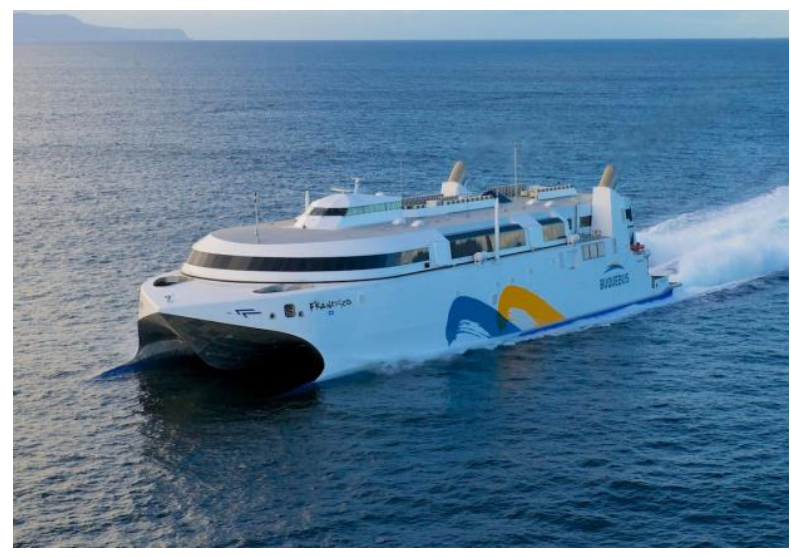

Figure 2: INCAT Hull 069 - Liquified Natural Gas (LNG) 99 m wave-piercer catamaran commissioned in June, 2013.

The severity of slamming can be significantly reduced with a centre bow, as in the INCAT wave-piercer catamaran (Figure 2), with substantial reserve buoyancy above the waterline. The wave-piercing design adopted by INCAT is configured to reduce wave response in moderate head seas while providing inherent forward buoyancy, which ensures 
that complete bow immersion of the demi-hulls and water over the upper deck of the central bow are avoided during large wave encounter or when overtaking following seas. It is an essential part of the vessel response that significant bow forces are generated in order to prevent deck diving and bow entry. Operations in severe sea conditions thus expose the vessel to wet deck slamming when the bow entry is sufficiently deep that the wet deck comes into contact with the water surface. Such extreme conditions with wet deck slamming need not necessarily present a hazard to the vessel or the passengers provided that the structure is adequately strong and loads are well sustained.

The hydrodynamic interaction between a moving wave-piercer bow and moving water surface is clearly a complicated process involving three-dimensional transients. For this reason identification of slam loads is best carried out by full-scale vessel trials and model testing as describe by Davis et al. (2007). However, continuing advancements in computing resource are enabling the application of simulations based on the Reynolds-averaged Navier-Stokes (RANS) equations (McVicar et al., 2014, 2015). The aim of the present paper is to give an overview of the various aspects of slamming in the bow area of Wave Piercing Catamarans by means of full scale sea trials, through scale model testing and through computation of transient hydrodynamics and structural response to impact loads. The combination of full scale, model scale and computational investigation gives a more comprehensive perspective on the wave slamming process for these vessels and its implication for structural design. This paper in particular extends previous investigations in the area of combined computation of both the transient hydrodynamics in the bow area and the dynamic response of the ship structure by finite element analysis.

\section{Review of wave slamming on full-scale vessels}

Sea trials have been conducted on several INCAT catamarans fitted with a TSK wave radar to measure wave elevation, accelerometers to measure vessel motion and strain gauges to measure unsteady stresses in the ship structure. Wave slamming causes an impulsive load on the structure resulting in virtually instantaneous flexure followed by whipping vibratory response as described by Kapsenberg and Brizzolara (1999). Slam impulse loads applied to the centre bow of the catamaran in head seas most strongly excite the first longitudinal mode of vibration in the vertical plane (Thomas et al., 2008). However, the very short duration of the slam impulse which acts on INCAT catamarans can induce responses from higher frequency modes (McVicar et al., 2015). The effect of higher order modes can be very localised and only observable in measurements close to the localised slam loading. Full-scale trials undertaken on the $112 \mathrm{~m}$ INCAT catamaran identified the first longitudinal modal frequency during an extreme wave slam (Lavroff et al., 2009). Figure 3 shows a typical accelerometer response during sea trials of INCAT hull 064 (112 
m) when a wet deck slam occurred (Lavroff, 2009). It is seen that the slam transient loading leads to excitation of the main whipping mode of the vessel, in this case at a frequency of $2.44 \mathrm{~Hz}$ or period of $0.41 \mathrm{~s}$. The decay of the whipping motion is due to internal frictional mechanisms within the structure (Thomas et al., 2008) and in this case indicates an overall structural damping ratio relative to critical damping of 0.065 .

Thomas et al. (2009) determined values of the first longitudinal bending mode frequency and damping ratio for $86 \mathrm{~m}$, $96 \mathrm{~m}, 98 \mathrm{~m}$ and $112 \mathrm{~m}$ INCAT wave-piercer catamarans at speed while encountering slams and while moored in calm water using anchor drop tests. Table 1 provides a summary. INCAT have developed a NASTRAN/PATRAN finite element model of the ship structure to predict frequencies of the main longitudinal bending mode - LBM (Figure 4), lateral torsional mode - LTM (Figure 5) and split mode - SM (Figure 6). The associated frequencies are shown in Table 1.

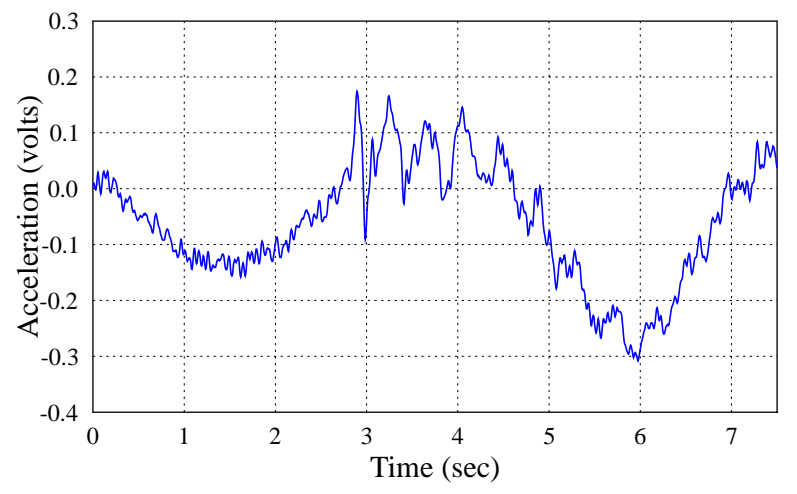

Figure 3: Wave induced slam upward acceleration recorded on the bow of INCAT Hull 064, $112 \mathrm{~m}$ wave piercer catamaran during a delivery voyage to Japan in August, 2007, Lavroff (2009). The slam occurred at time, $t=2.9 \mathrm{~s}$. Accelerometer sensitivity 0.78 Volts $/ g$, where $g$ is gravitational acceleration $\left(\mathrm{m} / \mathrm{s}^{2}\right)$.

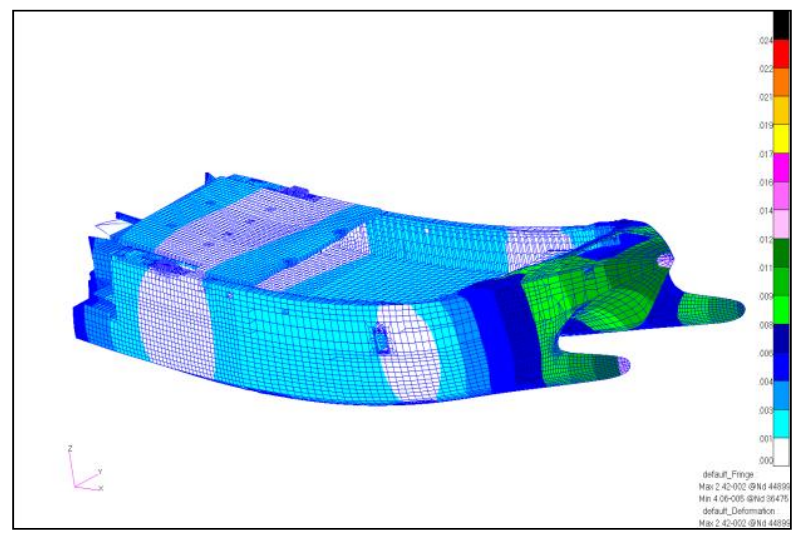

Figure 4: Finite element model of INCAT 98m vessel showing longitudinal bending mode (LBM), Davis et al. (2009b). 


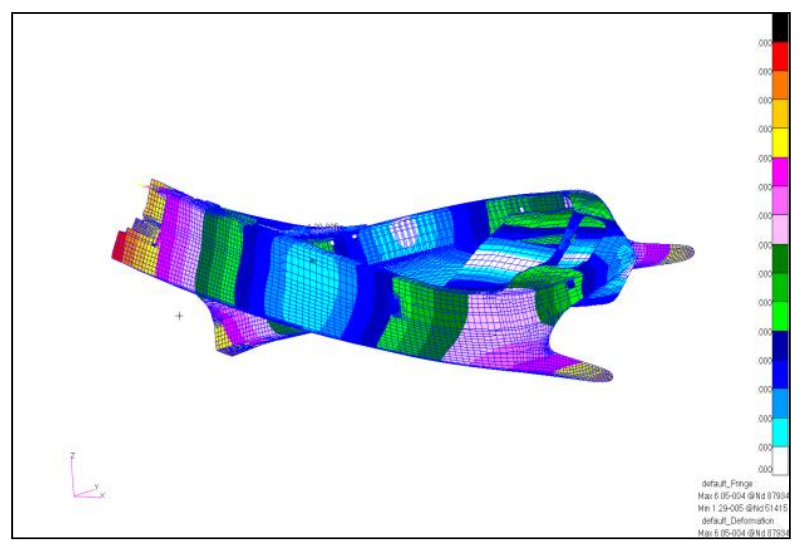

Figure 5: Finite element model of INCAT 98m vessel showing lateral torsion mode (LTM), Davis et al. (2009b).

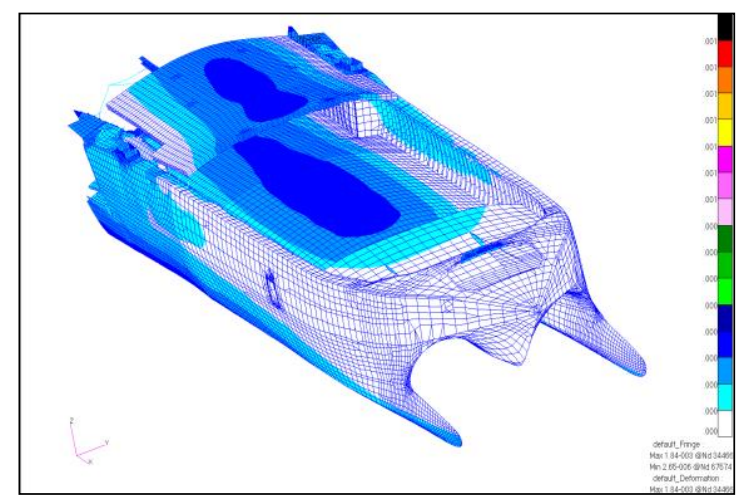

Figure 6: Finite element model of INCAT 98m vessel showing split mode (SM), Davis et al. (2009b).

The $98 \mathrm{~m}$ catamaran was analysed in more detail than the other vessels by Amin (2009). The finite element model predicted nine dominant longitudinal bending modes in the range $1.97-2.67 \mathrm{~Hz}$, five distinct split modes in the range $1.62-1.73 \mathrm{~Hz}$ and two lateral torsion modes at 1.10 and $1.13 \mathrm{~Hz}$. The various modes in each case can best be described as variants of the dominant mode, this being a particular characteristic of complex structures with dominant overall forms and dimensions. While the computed frequencies are generally higher than those measured, the finite element analysis clearly confirms the physical identity of the various modes. The fundamental LBM was observed in the whipping responses of all vessels while the LTM was only observable for the $86 \mathrm{~m}$ and $96 \mathrm{~m}$ vessels and the SM was only observed in the $98 \mathrm{~m}$ vessel sea trials. The $98 \mathrm{~m}$ catamaran had horizontal cross bracing on the portal top level extending further forward and further aft. This appears to have increased the lateral stiffness of the structure

10 therefore raising the response frequency of the split mode. Due to the general similarity of these vessels, it would be expected that similar modes be excited in each vessel. It is therefore likely that strain gauge placement and the

12 similarity of the LTM and SM frequencies inhibited the identification of the unobserved modes. The longitudinal bending modes of the $86 \mathrm{~m}$ and $96 \mathrm{~m}$ vessels were further identified in zero speed anchor drop tests using four 


\begin{tabular}{|c|c|c|c|c|c|c|c|c|c|}
\hline \multirow[t]{3}{*}{$\begin{array}{l}\text { INCAT } \\
\text { vessel }\end{array}$} & \multirow{2}{*}{\multicolumn{2}{|c|}{$\begin{array}{c}\text { Anchor Drop } \\
\text { Tests } \\
\text { LBM }\end{array}$}} & \multicolumn{4}{|c|}{ Sea Trials } & \multicolumn{3}{|c|}{$\begin{array}{l}\text { Finite Element Analysis } \\
\text { (FEA) }\end{array}$} \\
\hline & & & & & LTM & SM & LBM & LTM & SM \\
\hline & $f(\mathbf{H z})$ & $\varsigma$ & $\mathbf{f}(\mathbf{H z})$ & $\varsigma$ & $f(\mathbf{H z})$ & $f(\mathbf{H z})$ & $f(\mathbf{H z})$ & $f(\mathbf{H z})$ & $f(\mathbf{H z})$ \\
\hline $86 \mathrm{~m}$ & 3.01 & 0.035 & 2.6 & 0.055 & 1.5 & - & 3.00 & 1.65 & - \\
\hline $96 \mathrm{~m}$ & 2.89 & 0.018 & 2.8 & 0.036 & 1.3 & - & 2.95 & 1.50 & - \\
\hline $98 \mathrm{~m}$ & - & - & $\begin{array}{l}2.36- \\
2.60\end{array}$ & $\begin{array}{l}0.017- \\
0.032\end{array}$ & - & $\begin{array}{l}1.32- \\
1.72\end{array}$ & $\begin{array}{l}1.97- \\
2.67\end{array}$ & $\begin{array}{l}1.10- \\
1.13\end{array}$ & $\begin{array}{l}1.62- \\
1.73\end{array}$ \\
\hline $112 \mathrm{~m}$ & - & - & 2.44 & 0.065 & - & - & $2.1-2.65$ & - & - \\
\hline
\end{tabular}

accelerometers located along the vessel centre line by Thomas et al. (2003), as shown in Table 1. The finite element analysis showed little effect of speed using added water mass calculated by the boundary element method. Damping ratios are also presented in Table 1. Sources of damping were investigated by Thomas et al. (2008), who reported that hydrodynamic wave making, viscous effects and compressive pressure waves radiated through the body of the surrounding water are all negligible. It was concluded that major damping originates from structural sources such as the anti-vibration mountings that isolate the upper passenger deck structure from the main ship structure, bolted connections, the internal fit-out and furnishings.

Table 1: Modal frequencies $(f)$ and damping ratios $(\varsigma)$ for full-scale Wave-Piercer INCAT Catamarans. LBM: Longitudinal Bending Mode. LTM: Lateral Torsion Mode. SM: Split Mode. Anchor drop tests are at zero speed; wave slam responses are at speeds between 10 and 30 knots (86m), 12 and 25 knots $(96 \mathrm{~m}), 32$ knots (98m) and 35 knots (112 m); FEA values include water added mass and neglect forward speed effects (Kapsenberg and Brizzolara, 1999; Davis et al., 2009a; Amin, 2009). Ranges for the 98m and $112 \mathrm{~m}$ vessels represent different loading from light ship to full design load.

\section{Hydroelastic segmented catamaran model}

Owing to the complexity of the interacting unsteady hydrodynamic and structural responses in the geometrically complicated bow region of the wave piercing catamaran, physical model testing under controlled wave encounter conditions forms an essential part of the investigation of the wave slamming process. Whilst full scale sea trials 
testing gives a broad indication of the general nature of the wave slam process, sea conditions cannot be accurately controlled at full scale and so information gained at full scale is inevitably restricted. Therefore scale model testing is undertaken as part of this investigation. A $2.5 \mathrm{~m}$ hydroelastic segemented catamaran model was developed based on the $112 \mathrm{~m}$ INCAT wave-piercer catamaran design to measure the wave loads during slamming as well as the motions response in head-seas. Table 2 summarises key parameters at model and full scale, the dimensionless encounter frequency being $\omega_{e}^{*}=\left(2 \pi f_{e}\right) \sqrt{L / g}$ where $f_{e}$ is the wave encounter frequency $(\mathrm{Hz}), g$ is acceleration due to gravity $\left(\mathrm{m} / \mathrm{s}^{2}\right)$ and $L$ is the overall hull length $(\mathrm{m})$.

\begin{tabular}{|c|c|c|}
\hline Parameter & Full scale & Model scale \\
\hline Overall length & $112 \mathrm{~m}$ & $2.5 \mathrm{~m}$ \\
\hline Displacement & 2500 tonnes & $27.1 \mathrm{~kg}$ \\
\hline $\begin{array}{c}\text { Longitudinal centre of gravity (LCG) } \\
\text { from transom }\end{array}$ & $42.47 \mathrm{~m}$ & $0.948 \mathrm{~m}$ \\
\hline Pitch radius of gyration (RoG) & $28.5 \mathrm{~m}$ & $0.635 \mathrm{~m}$ \\
\hline Top speed & $20.6 \mathrm{~m} / \mathrm{s}$ & $2.89 \mathrm{~m} / \mathrm{s}$ \\
\hline Medium speed & $10.6 \mathrm{~m} / \mathrm{s}$ & $1.53 \mathrm{~m} / \mathrm{s}$ \\
\hline Bending mode frequency & $2.44 \mathrm{~Hz}$ & $13.8 \mathrm{~Hz}$ \\
\hline Dimensionless wave encounter frequency & 3.5 to 7.5 & 3.5 to 7.5 \\
\hline Wave encounter frequency & 0.165 to $0.363 \mathrm{~Hz}$ & 1.10 to $2.36 \mathrm{~Hz}$ \\
\hline
\end{tabular}

Table 2. Main parameters at model and full scale

In comparison with full-scale trials, model experiments provide a more controlled and highly instrumented and regular wave slam test condition that is not possible at full-scale. In particular, model experiments make possible a comprehensive investigation of extreme wave slam loads as reported by Lavroff et al. (2013). It is never certain in full-scale trials whether the most severe structural loading has been identified. However, there is a need to verify that slamming is correctly simulated at model scale and to this end the model test work was aimed to represent the hydroelastic response of the ship structure so that the dynamic interactions between the wave slam and the ship structure are effectively represented. Practically, modeling of the continuous variation of stiffness throughout a ship structure cannot be exact and therefore a segmented hydroelastic model was developed following similar design methodologies to those of McTaggart et al. (1997), Hermundstad et al. (1999), Hermundstad et al. (1995) and Kapsenberg and Brizzolara (1999). The general layout of the model is shown in Figure 7 and a photograph of the model is shown in Figure 8. 


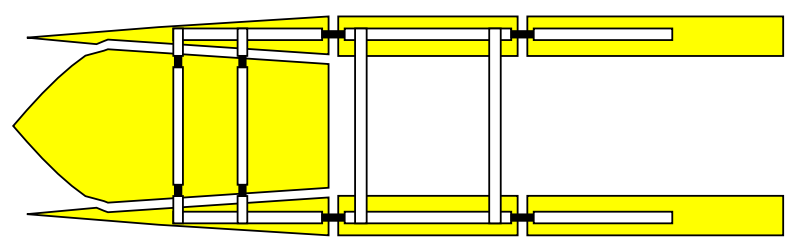

$59 \quad$ Figure 7: $2.5 \mathrm{~m}$ hydroelastic segmented catamaran model layout plan.

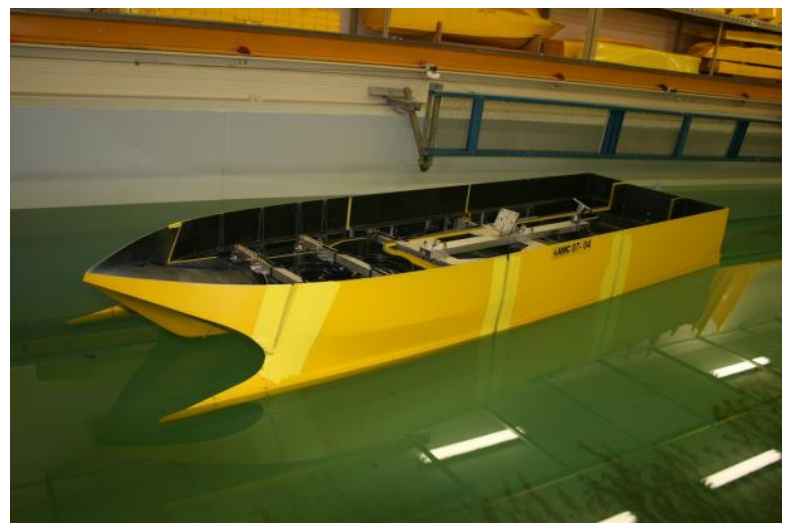

62 Figure 8: $2.5 \mathrm{~m}$ hydroelastic segmented model of the 112m INCAT wave-piercer catamaran.

63

As shown in Figure 7 the catamaran model was configured into six separate segments: the midship segment comprising the midship demi-hull sections joined by a relatively rigid transverse aluminium frame, two aft demi-hull sections, two forward demi-hulls and a separate centre bow segment. Hollow aluminium backbone beams are rigidly mounted within each hull segment and the segments are connected by machined inserted links (Figure 9) bolted with integral plug pieces into the ends of the backbone beams. Each link had an integral square section connecting the bolted plugs with dimensions selected to give the overall connection the required stiffness to simulate the whipping mode frequency correctly. Because of symmetry under head seas testing the two aft demi-hulls essentially moved in unison during bending vibration and similarly the two forward demi-hulls moved together. The centre bow was constructed as a separate segment so as to isolate the wave slam loads acting on the bow and was also mounted on hollow beams with flexible mounting links at cuts in these transverse bow mounting beams instrumented with strain gauges. The three main demi-hull segments were connected by elastic links of appropriate stiffness to match the first longitudinal bending mode natural frequency and instrumenting with strain gauges (Figure 9) enabled the dynamic measurement of longitudinal bending moments at the segment joins. The centre bow was mounted on two transverse aluminium beams (Figure 9), each incorporating two smaller elastic hinges instrumented with strain gauges (Figure 7). The centre bow transverse beams were mounted on the forward segments of demi-hulls joined by pin connections 
located on the aluminium backbone beams. There was negligible frictional moment about the forward and aft pin connections between the demi-hull backbone beams and the transverse beams so that the bending moment measured at each of the centre bow elastic hinges could be used to determine the magnitude of the vertical shear force in each transverse beam. Use of two beams made possible the calculation of the total vertical slam force acting on the centre bow and its longitudinal point of action. The stiffness of the transverse beams and elastic hinges was designed such that the predicted frequency of the first mode of the centre bow was about three times greater than the frequency of the main longitudinal bending mode. Despite the significantly increased stiffness and hence frequency of the modes associated with centre bow motion, slamming did initiate an impulse response from the centre bow vibration mode. However, the slam excitation response of the centre bow on its mountings was only evident locally and higher frequency modes such as this were strongly damped and did not appear to affect the demi-hull results of Lavroff (2009).

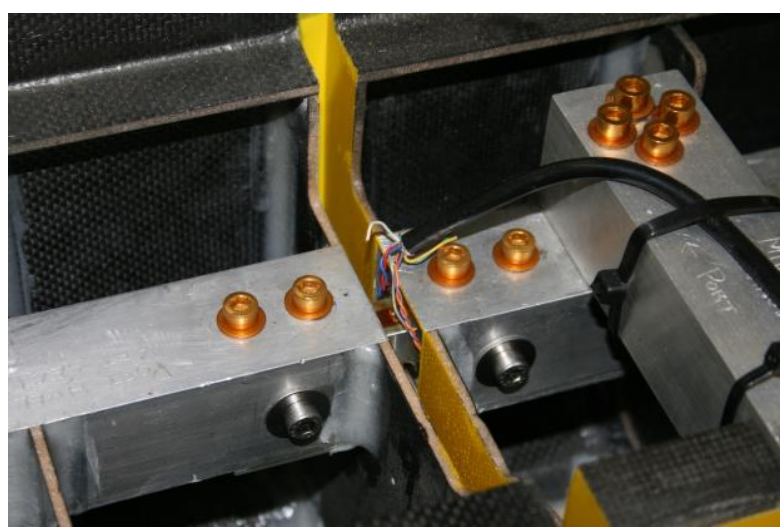

92 Figure 9: Strain gauges on the demi hull elastic hinges for the measurement of hull bending moments.

The weight of the aluminium square hollow section beams and elastic hinges together with the relatively large centre bow made the overall weight and trim of the model a critical aspect of the design. Therefore the model was manufactured using carbon fibre and Divinicell ${ }^{\mathrm{tm}}$ foam sandwich construction to reduce weight. Approximately $4 \mathrm{~kg}$ of ballast was needed to achieve a total design model mass of $27.1 \mathrm{~kg}$. The ballast was located near the stern of the aft demi-hull segments so that the catamaran model would achieve level trim in calm water at zero speed. The resulting pitch radius of gyration was measured to be $25.4 \%$ of the overall length of the model.

The catamaran model was primarily designed for testing in regular waves at high-speed in the $100 \mathrm{~m}$ towing tank of the Australian Maritime College in head seas only and so no attempt was made to model the lateral bending mode or split modes. It was not expected that these modes would be excited during towing tank testing as Thomas (2003) 
found that only the lateral torsion mode was present during sea trials of an $86 \mathrm{~m}$ catamaran in oblique seas at $1.5 \mathrm{~Hz}$, the main longitudinal bending mode being at $2.6 \mathrm{~Hz}$ (Table 1). The target of the model design was to achieve a main longitudinal bending frequency of $13.79 \mathrm{~Hz}$ at model scale calculated based on data measured on the $86-98 \mathrm{~m}$ fullscale vessels as the first $112 \mathrm{~m}$ catamaran had yet to be commissioned at the time the catamaran model was being designed and constructed. Finite element analysis of the full-scale $112 \mathrm{~m}$ catamaran design subsequently revealed a set of longitudinal bending modes ranging from $2.1 \mathrm{~Hz}$ to $2.65 \mathrm{~Hz}$ at full scale (Table 1). The limited sea trials data available for the $112 \mathrm{~m}$ vessel has indicated a first longitudinal bending mode of $2.44 \mathrm{~Hz}$ at full scale (Figure 3) being towards the upper end of the predicted frequency range. Notwithstanding these results, the segmented model natural frequency was based on the original prediction of a full-scale $112 \mathrm{~m}$ vessel longitudinal mode frequency of $2.06 \mathrm{~Hz}$ at full scale based on scaling the vibration frequencies measured on previous vessels presented in Table 1.

The first longitudinal bending mode frequency of the model was predicted by Lavroff et al. (2007a) at the design stage using a three degree of freedom theoretical model with the expected mass distribution, the added water mass and the measured stiffness of the elastic hinges. The stiffness of the elastic hinges was corrected on the same basis as had been undertaken on a previous monohull NPL6a segmented model (Holloway et al., 2006; Lavroff et al. 2007a) to allow for the inherent flexibility of the hull and backbone beam causing significant bending between the mounting points across each segment of hull in addition to bending within the connecting links. The construction of both hydroelastic models was generally similar, although the present catamaran model was manufactured using carbon fibre to reduce weight and increase stiffness whereas fibreglass was used for the NPL6a model. A theoretical analysis (McVicar et al,, 2014) of the segmented catamaran model yielded three modes, one zero frequency rigid body mode and two longitudinal flexural modes. The first longitudinal mode was the mode of interest with a modal frequency of 14.5 $\mathrm{Hz}$ and the second longitudinal modal frequency was $32.0 \mathrm{~Hz}$ at model scale. The corresponding mode shapes are shown in Figure 10. The second mode was not clearly evident in the strain response signals as a consequence of the slam location being near the forward node of this mode so that there is little energy transfer from the loading into the mode. 

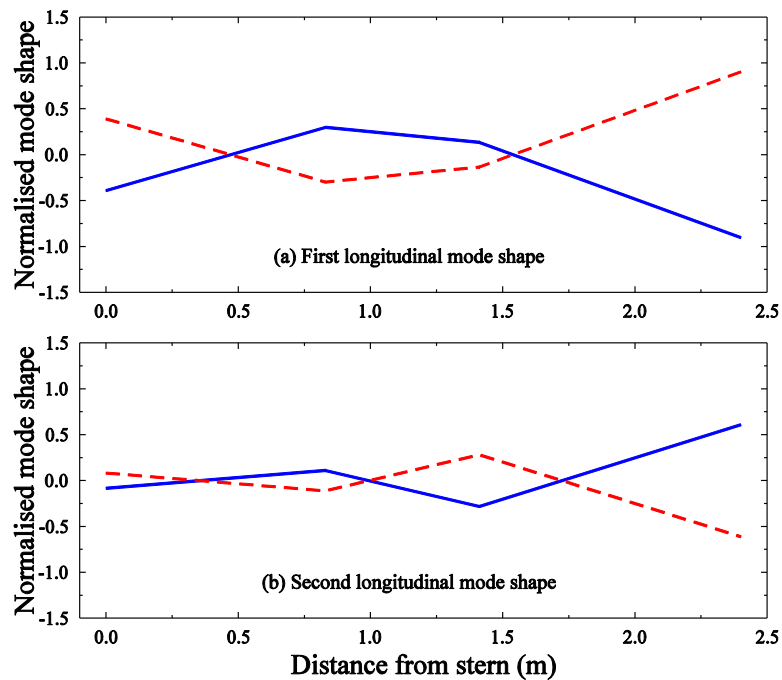

131 Figure 10: Theoretical mode shapes of the segmented model in still water at zero speed (first mode at $14.5 \mathrm{~Hz}$ and second mode at $32 \mathrm{~Hz}$ ).

\section{Bending vibratory response of the hydroelastic segmented catamaran model}

All model experiments were carried out in the 100m long Australian Maritime College towing tank in Launceston, Australia with a water depth of $1.4 \mathrm{~m}$ (https://www.amc.edu.au/maritime-engineering/towing-tank). Strain gauges mounted on the top and bottom of each elastic hinge recorded the differential strain. Analogue signals were sampled at $500 \mathrm{~Hz}$ and digitized by a National Instruments (NI) CompactRIO (cRIO) running Labview FPGA. The strain gauge signals were acquired by a NI cRIO-9237 strain gauge module specifically developed for the acquisition of differential strain. After each run digital data from the cRIO was downloaded via Ethernet to a laptop PC running Labview. Model heave and pitch motions were measured using linear variable differential transformer (LVDTs) located on the forward and aft tow posts of the catamaran model (Lavroff, 2009) while wave profile data was collected using both resistance and acoustic type wave probes mounted on the towing tank carriage, the former being located at the plane of the model LCG. These analog signals were amplified to an output of \pm 10.0 Volts per channel (reference single ended), sampled at $100 \mathrm{~Hz}$ and digitized using a National Instruments DAQ card input to a desktop PC also running Labview. A 9 Volt DC trigger signal was used to synchronise the two systems.

Wet and dry vibration experiments were undertaken to investigate the influences of the effective stiffness and mass on the first longitudinal bending frequency by Lavroff et al. (2007b). Dry experiments were undertaken by suspending the model in air using long elastic straps and applying manual impulse loads to the bow. A similar excitation was adopted for wet experiments with the catamaran model in calm water at forward speeds ranging from $0-2.89 \mathrm{~m} / \mathrm{s}$. 
Vibration experiments were repeated with an instrumented impact hammer by McVicar et al. (2014) in air and in calm water as part of a system identification process. Figure 11 shows a typical transient record of bending in the demi-hull elastic hinges at a design displacement of $27.1 \mathrm{~kg}$ using the instrumented impact hammer tests at zero speed in calm water, the first longitudinal bending mode being evident at a frequency of $13.8 \mathrm{~Hz}$ and the second modal frequency was observed at $30.9 \mathrm{~Hz}$. The differential strain measured at each demi-hull elastic hinge showed a decaying vibratory response, this being very similar to the whipping vibration response identified on full-scale vessels as reported by Thomas et al. (2003) and also observed in the model tests conducted on the NPL6a hull by Lavroff et al. (2007a) and Dessi et al. (2009).

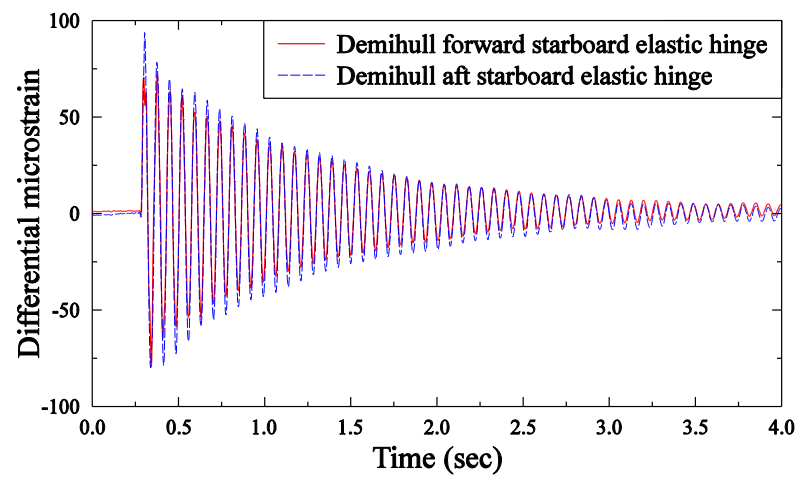

Figure 11: First longitudinal mode response of the hydroelastic segmented catamaran model to impact hammer excitation at the forward node of the second longitudinal mode during vibration experiments in calm water at zero speed.

The mode shape (Figure 12) was determined by applying impulsive loads using an instrumented impact hammer at the forward node of the second bending mode and measuring the accelerations using Bruel and Kjaer Type 4334 accelerometers located at incremental positions along the segmented model (McVicar et al., 2014) on both the port side and starboard sides of the model. The vibration amplitudes at the identified first longitudinal bending frequency were then extracted from each of the identified inertance frequency response functions to generate a mode shape. Figure 10 and Figure 12 show reasonable agreement between the mode shapes predicted by the theoretical model 172 (McVicar et al., 2014) and measured on the physical model. When compared to full-scale measurements (Figure 13) it can be seen that the model experiments provided a good approximation of the vibration response to wave slam excitation, Thomas et al. (2008). 


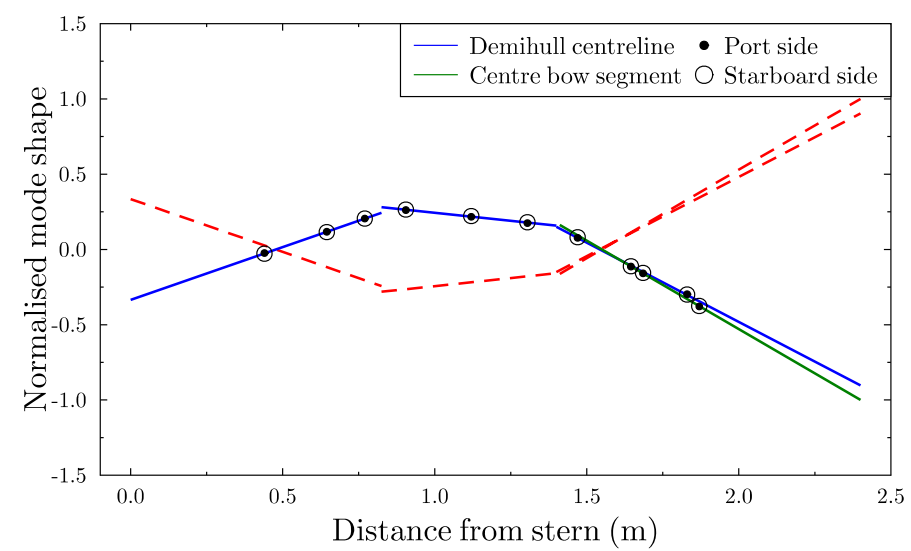

176 Figure 12: First longitudinal mode shape of the catamaran model in calm water experimentally measured at a frequency of $13.8 \mathrm{~Hz}$. The blue lines represent the demi hull and the green line represents the centre bow, the red 178 dashed lines represent the negative shape of the response for both demi hulls and centre bow.

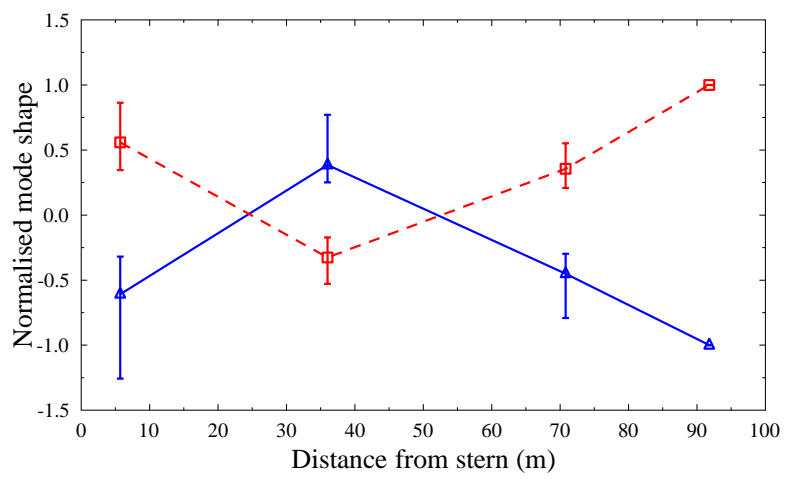

181 Figure 13: First longitudinal mode shape of INCAT Hull $050-96 \mathrm{~m}$ full-scale catamaran in calm water measured at

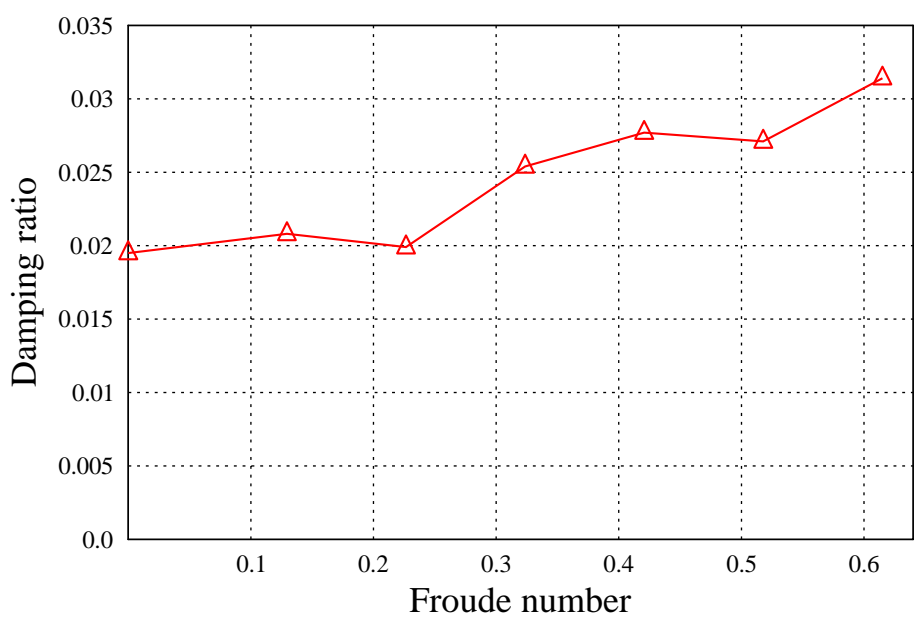

185 Figure 14: Damping ratio of the catamaran model in calm water as a function of Froude number. 
The calm water whipping experiments over the speed range $0-2.89 \mathrm{~m} / \mathrm{s}$ showed a first mode frequency of 13.65 $\pm 0.15 \mathrm{~Hz}$, which was very close to the target frequency of $13.79 \mathrm{~Hz}$ and showed no discernible effect of forward speed (Lavroff et al., 2009). The damping ratio however increased overall by $65 \%$ over the same speed range, as seen in Figure 14. Similar speed effects were identified by Dessi et al. (2005) on a hydroelastic segmented monohull model.

Damping of the main longitudinal bending mode of the catamaran model is very close to that of the $96 \mathrm{~m}$ INCAT catamaran (Table 1) at zero speed and at top speed in sea trials. This similarity was fortuitous as the damping in both cases was largely associated with the structure and attachments and was therefore not easily controlled.

\section{Wave slam loads identified by towing tank tests}

The aim of the model test program was to investigate the slamming response of the $112 \mathrm{~m}$ catamaran wave-piercer design. Two main issues need to be considered with modeling: the extent to which model tests simulate real full scale slamming, and the overall variation of slamming frequency and magnitude during operation in severe seas. These underlying issues require the identification of key slam parameters, such as the magnitude, location, distribution and duration of wave slam loads on the centre bow and wet deck region, and the total impulse applied to the structure. The slam impulse also transmits energy into the whipping vibrations (Lavroff, 2009). The duration of this dynamic transient event would be expected to be strongly related to the periods of the excited modes. Therefore faithful representation of the modal response of the segmented model, as described previously, is an important aspect of the test model if energy transmission into the whipping mode is to be evaluated by means of model testing.

Figure 15 shows a photo taken during a typical slam in regular waves on the $2.5 \mathrm{~m}$ model of the INCAT $112 \mathrm{~m}$ wavepiercer design. It is observed that lateral water jets form as the centre bow contacts the free surface. This is a feature of a process that becomes complicated in the area between the centre bow, jaws (where the centre bow joins the top of the demi-hulls) and forward wave-piercing demi-hulls. Some INCAT designs have moved the jaws aft to assist the

214 lateral displacement of water, but although this may assist in streamlining the flow, additional structural reinforcement of the wave-piercing bows is required, which may not be a practical solution from a structural strength point of view as lateral vibration of the demi-hulls forward of the jaws can occur. Early lateral displacement of water 
is also achieved with a centre bow keel that has a low deadrise angle (Whelan, 2004), this being a feature introduced

218 to more recent INCAT designs.

220 While the visual appearance of the slam with respect to the geometry of the centre bow may give some indication of 221 how the loads might be distributed, it is more critical for structural analysis to identify the magnitude and precise 222 location of the slam load. Hydroelastic model loads in regular seas were measured in up to $120 \mathrm{~mm}$ waves at two speeds to develop an understanding of the wave loads possible on the $112 \mathrm{~m}$ INCAT wave-piercer catamaran design in seas up to $5.3 \mathrm{~m}$ wave height at full scale $(120 \mathrm{~mm}$ at model scale) and at speeds of 20 knots and $38 \mathrm{knots}(1.53 \mathrm{~m} / \mathrm{s}$ and $2.89 \mathrm{~m} / \mathrm{s}$ at model scale). This represents conditions somewhat beyond the range used by civilian operators where operation in seas up to $3 \mathrm{~m}$ or $4 \mathrm{~m}$ have been adopted by different operators. Military operators have operated in larger seas but seas around $5 \mathrm{~m}$ at the lower speed were considered here as a practically realistic limitation even for military operations. Figure 16 and Figure 17 show examples of strain data from the centre bow and demi-hull elastic hinges during regular seas tests.

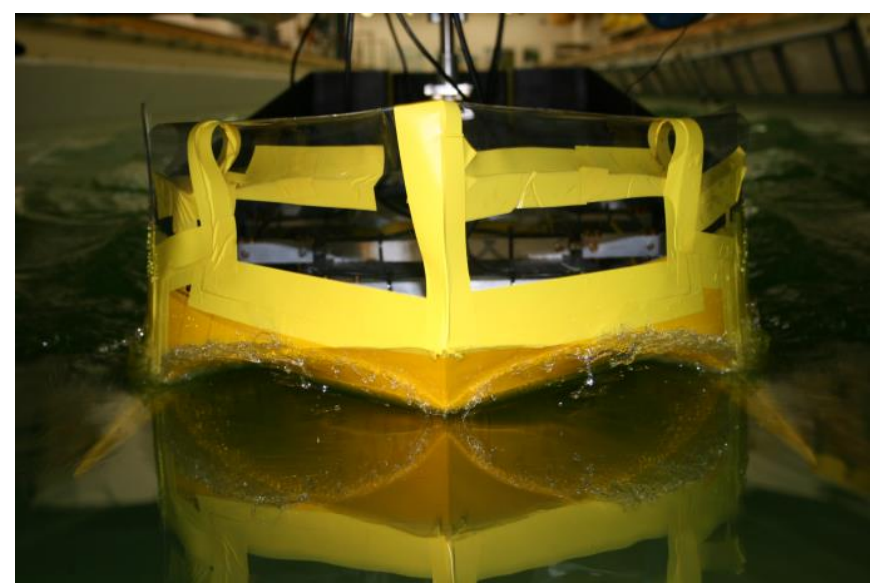

231 Figure 15: Wet deck slam event during towing tank testing of the $2.5 \mathrm{~m}$ catamaran model at a speed of $1.53 \mathrm{~m} / \mathrm{s}$ in 90 $\mathrm{mm}$ waves at dimensionless wave encounter frequency, $\omega_{e}{ }^{*}=5.15$.

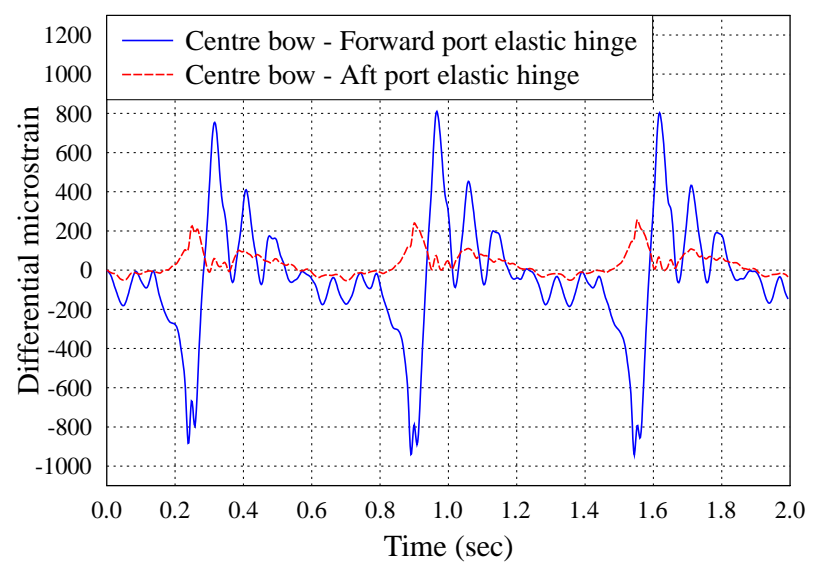


Figure 16: Centre bow strain gauge data obtained at a model test speed of $1.53 \mathrm{~m} / \mathrm{s}, 90 \mathrm{~mm}$ wave height and 235 dimensionless wave encounter frequency $\omega_{e}{ }^{*}=4.84$, low-pass filtered at $30 \mathrm{~Hz}$.

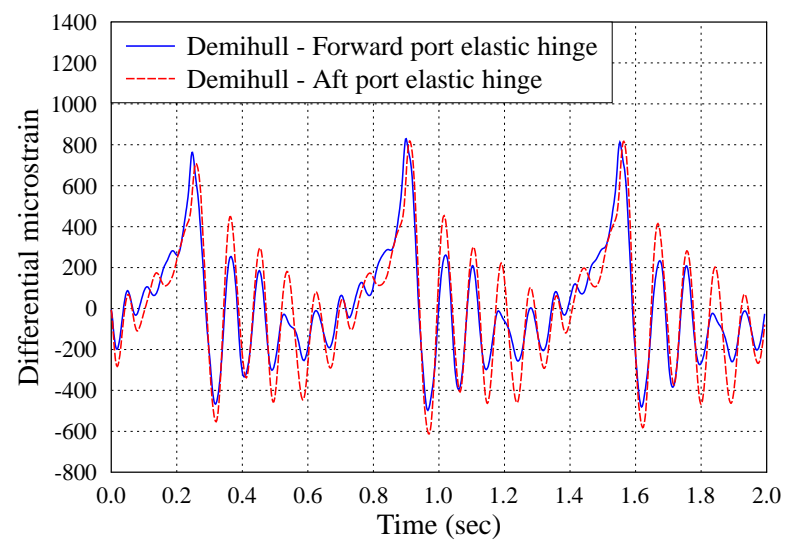

Figure 17: Demi-hull strain gauge data obtained at a model test speed of $1.53 \mathrm{~m} / \mathrm{s}, 90 \mathrm{~mm}$ wave height and dimensionless wave encounter frequency $\omega_{e}{ }^{*}=4.84$, low-pass filtered at $30 \mathrm{~Hz}$.

Figure 16 and Figure 17 show highly repeatable slams in regular waves. Each slam impulse is followed by whipping dominated by the decaying first longitudinal mode of vibration with evidence of higher order modes early in the response, particularly in the centre bow response. The data shown are the difference between the strain gauges located on the top and bottom surfaces of the elastic hinge. The two gauges on each hinge were connected in a half bridge such that the output could be calibrated directly in terms of the applied bending moment (Lavroff, 2009). The calibration factor was very close to that predicted from the hinge material properties and cross section. Similar data were obtained from the elastic hinges mounted on the centre bow transverse beams and these made possible the calculation of the time-varying vertical slam force acting on the bow and its effective force centre. Amin (2009) in separate experiments on the same model measured vertical accelerations to assess the relative magnitude of the centre bow inertia loads. The inertia load during slamming due to the centre bow mass was estimated as $17 \%$ of the measured wave impact load at peak slamming (Lavroff 2009). In smaller wave conditions Shahraki (2014) has implemented an inertia correction to the measured loads on a similar segmented model by measuring the linear acceleration at the local segment LCG. In doing so, Shahraki was able to eliminate the effect of the inertial loading when the centre bow was out of the water, but further work is necessary to confirm that a single acceleration measurement is sufficient for inertia correction when the centre bow segment is immersed.

Although the first longitudinal bending mode frequency remained unchanged with increasing Froude number in calm water (Lavroff et al., 2009), Figure 18 shows that over the range of encounter frequencies considered, the whipping 
frequency increases with wave encounter frequency. Furthermore the whipping frequency in calm water was

259 significantly higher than during slamming. This is a result of increased bow penetration and increased modal added mass during slamming, particularly at the lower encounter frequencies (Lavroff, 2009).

The model tests provided the basis for determining the time varying hydrodynamic force on the centre bow in both sagging (peak upward force) and hogging (peak downward force) during slam impact. In addition to the experimental data, the slam loads, location and pressure distribution were estimated for the same conditions at model scale through RANS based numerical simulation using the commercially available software package Star-ccm+ (McVicar et al., 2014; McVicar et al., 2015) based on rigid body analysis to determine peak sag. Figure 19 shows the variation of the peak slam force with encounter frequency in regular waves, while Figure 20 shows its position based on the comparison between both experimental and numerical results. The pressure distribution was also predicted using the RANS based numerical simulation as shown in Figure 20.

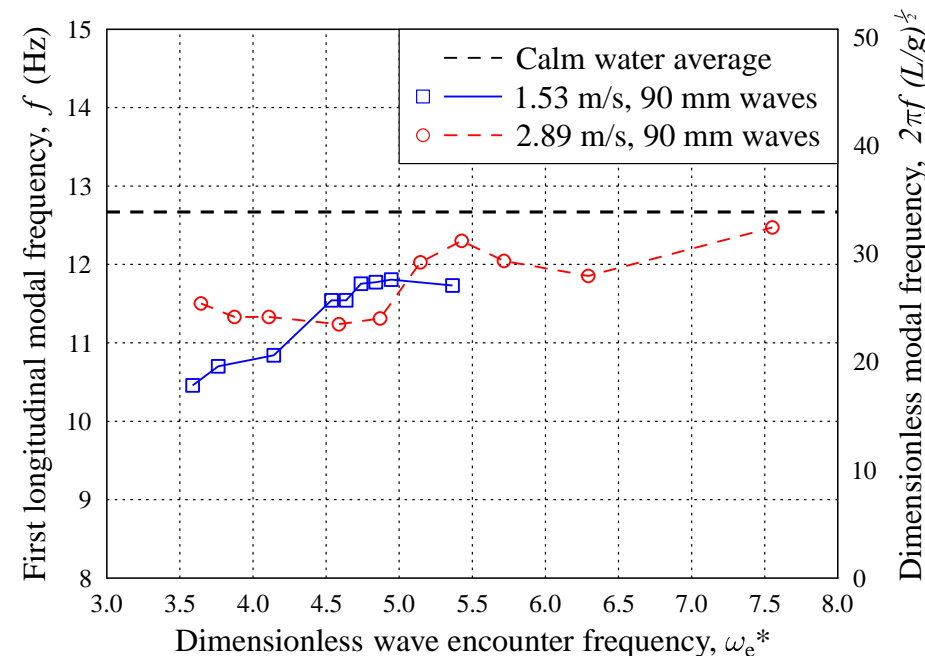

Dimensionless wave encounter frequency, $\omega_{\mathrm{e}}$ *

272 Figure 18: First longitudinal modal frequency of the hydroelastic catamaran model as a function of dimensionless wave encounter frequency in $90 \mathrm{~mm}$ waves at test speeds of $1.53 \mathrm{~m} / \mathrm{s}$ and $2.89 \mathrm{~m} / \mathrm{s}$. Right hand axis: modal frequency non-dimensionalised on the basis of modal frequency $f(\mathrm{~Hz})$, overall model length $L(\mathrm{~m})$ and gravity, $g\left(\mathrm{~m} / \mathrm{s}^{2}\right)$. 


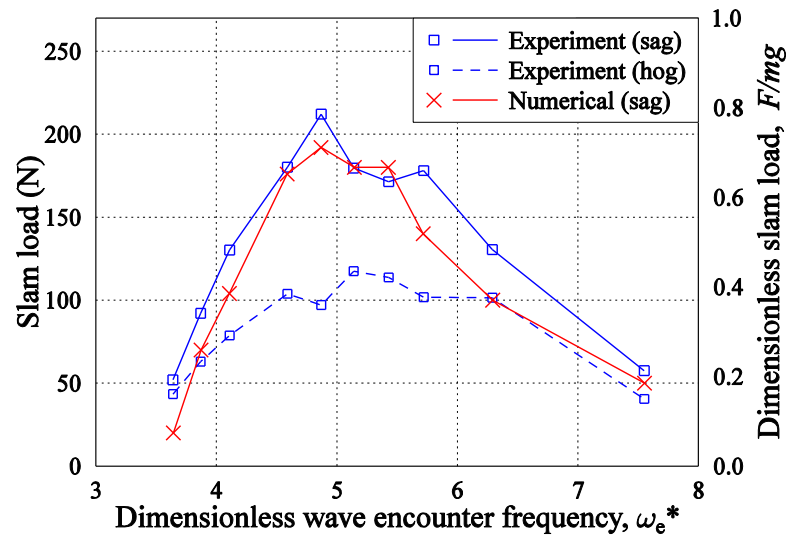

276 Figure 19: Peak slam loads on the bow of the $2.5 \mathrm{~m}$ segmented scale model of the $112 \mathrm{~m}$ INCAT wave-piercer catamaran at a model test speed of $2.89 \mathrm{~m} / \mathrm{s}$ in $90 \mathrm{~mm}$ waves: experimental results and numerical RANS based predictions. Right hand axis: slam load non-dimensionalised on the basis of slam force $F(\mathrm{~N})$, mass, $m(\mathrm{~kg})$, and gravity, $g\left(\mathrm{~m} / \mathrm{s}^{2}\right)$. Sag is upward force, hog is downward force on the bow.

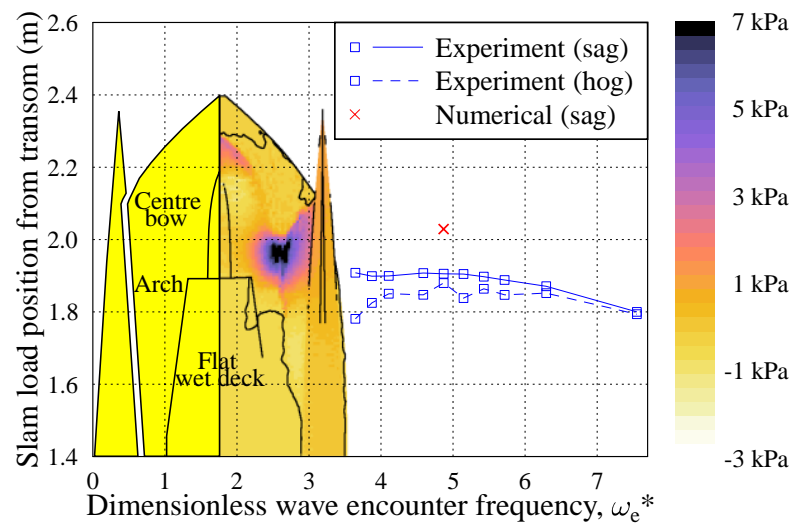

Figure 20: Centre bow peak slam load position (experiment and numerical) and slam pressure (numerical) at a model test speed of $2.89 \mathrm{~m} / \mathrm{s}$ in $90 \mathrm{~mm}$ waves.

It is observed from these figures that slamming only occurred over a limited range of encounter frequencies in regular seas and that the position of the maximum slam force, found to be in the arch section of the centre bow, moved slightly aft with increasing wave encounter frequency. The RANS simulation (McVicar et al., 2015) predicts the slam force to act somewhat further forward than was observed experimentally whilst the centre of pressure in the arch was identified at $1960 \mathrm{~mm}$ from the stern with a peak pressure magnitude of $8.32 \mathrm{kPa}$ at model scale. The range of frequencies over which slamming occurs was similar to that in the RANS simulation and was found to overlap significantly with the frequency range of strong vessel motions reported by Davis and Holloway (2007) and Davis et al. $(2004,2005)$. It thus follows that slamming is strongly associated with the vertical motion of the centre bow (Lavroff and Davis, 2015). 
294 Figure 19 shows a maximum experimental model scale slam force of $212 \mathrm{~N}$ and a maximum numerical slam force of $192 \mathrm{~N}$ in $90 \mathrm{~mm}$ waves at $2.89 \mathrm{~m} / \mathrm{s}$ (the highest speed tested) and at a dimensionless wave encounter frequency of 4.87. However, the maximum slam over all experimental model tests was slightly higher at $229 \mathrm{~N}$, measured in 120 $\mathrm{mm}$ waves at $1.53 \mathrm{~m} / \mathrm{s}$ (Lavroff and Davis, 2015). This slam had an overall model scale duration of $0.17 \mathrm{~s}$ (measured

298 from time of centre bow entry to time of peak hogging force) and an overall model scale impulse (determined by integrating the slam force with time) of $15.0 \mathrm{Ns}$ (Lavroff and Davis, 2015). Scaled to the $112 \mathrm{~m}$ vessel (Thomas et al., 2010) these correspond to a peak slam force of 2150 tonnes weight $(21.09 \mathrm{MN})$ over $1.14 \mathrm{~s}$ with an impulse of 938 tonne weight-seconds (9.20 MNs) in $5.4 \mathrm{~m}$ waves at 20 knots. A similar peak slam force of 2250 tonnes weight (22.07MN) has been reported on a $96 \mathrm{~m}$ full scale INCAT catamaran by Amin et al. (2009). This is significantly larger than the extreme slam load reported by Thomas (2003). However the latter slam was asymmetric, loading only the starboard side between the centre bow and demi-hulls, whereas the slam identified by Amin et al. (2009) was in approximately controlled seas trials in head seas and would be expected to load both arches causing much greater loads as identified. Nevertheless, there can be no certainty that slams observed in the full scale trials correspond to head sea direction exactly.

The slam impulses reported by Amin et al. (2009) reached a maximum value of 286 tonne weight-seconds (2.81 MNs), appreciably lower than values obtained from model tests. This may be due to several reasons. Firstly, the maximum slam forces reported by Lavroff (2009) were in 5.4 m equivalent seas whereas seas in the full-scale trials reported by Amin et al. (2009) were about $3.5 \mathrm{~m}$. Secondly, the determination of the slam impulse strongly depends upon the signal analysis, in particular the choice of the points in time between which the slam is taken to occur. Amin et al. (2009) established these times to be when the strain records crossed the standard deviation level of the underlying global wave loading. This may have reduced the time interval assigned to the impulse calculation by comparison with the procedure adopted by Lavroff (2009), who identified the slam relatively earlier as the incident wave was regular. Thirdly, the towing tank tests were carried out in controlled regular wave conditions, whereas the waves encountered at full-scale are not regular. Thus, it is not entirely clear that the sea trials data may necessarily represent the most extreme wave slamming impulse. The towing tank test program did, however, expose the model to severe operating conditions with respect to the duration and impulse of the slam compared to that measured at fullscale. While the maximum slam forces measured on the model were found to scale reasonably well, it was evident that the maximum slam loads did occur at regular wave encounter frequencies that strongly coincided with maximum vessel motions (Lavroff, 2009; Davis et al., 2005; Davis et al., 2004). 


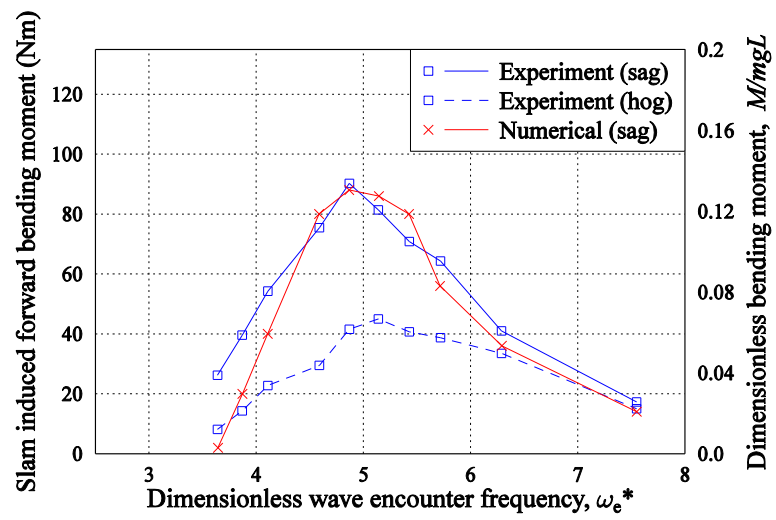

325 Figure 21: Slam induced peak vertical bending moment on the demi-hull at the forward segment position as a function of dimensionless wave encounter frequency at a model test speed of $2.89 \mathrm{~m} / \mathrm{s}$ in $90 \mathrm{~mm}$ waves: experimental results versus numerical RANS based predictions. Right hand axis: bending moment non-dimensionalised on the basis of slam induced bending moment $M(\mathrm{Nm})$, model mass, $m(\mathrm{~kg})$, gravity, $g\left(\mathrm{~m} / \mathrm{s}^{2}\right)$ and model length $L(\mathrm{~m})$.

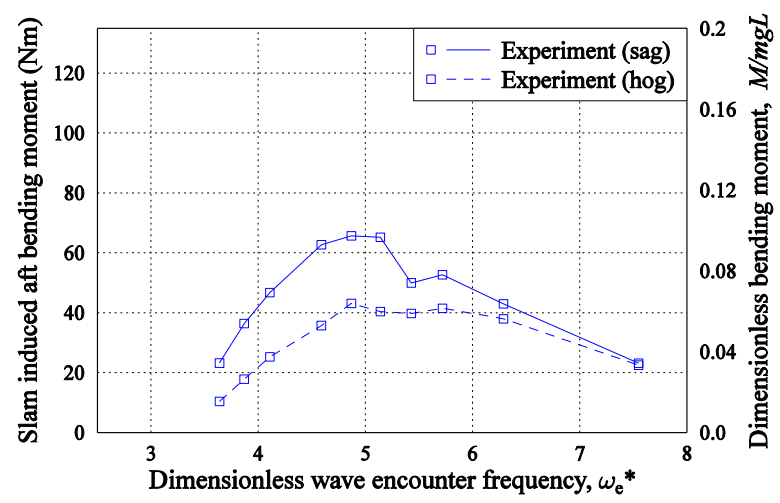

Figure 22: Slam induced peak vertical bending moment on the demi-hull at the aft segment position as a function of dimensionless wave encounter frequency at a model test speed of $2.89 \mathrm{~m} / \mathrm{s}$ in $90 \mathrm{~mm}$ waves. Right hand axis: bending moment non-dimensionalised on the basis of slam induced bending moment $M(\mathrm{Nm})$, model mass, $m(\mathrm{~kg})$, gravity, $g$ $\left(\mathrm{m} / \mathrm{s}^{2}\right)$ and model length $L(\mathrm{~m})$.

The final aspect of the slamming investigated was the direct influence of the slam load on the model bending. This was evident when comparing the slam induced bending moments (Figure 21 and Figure 22) with the slam load (Figure 19). The energy imparted by the slam was also considered through the analysis of the strain energy in the segmented model elastic hinges (Lavroff and Davis, 2015). This represented the energy available for transfer into the whipping vibration. It was found over the full range of model tests that this reached a maximum of $0.97 \mathrm{~J}$, which extrapolates to a full-scale energy of about $4 \mathrm{MJ}$, only slightly larger than the $3.5 \mathrm{MJ}$ estimated by Amin et al. (2009) 
in sea trials. The results indicate that the hydroelastic model has simulated the input of energy into whipping reasonably well.

\section{Conclusions}

Segmented model tests, full scale sea trials and numerical RANS simulations have been used as a basis for identifying the wave impact loads acting on wave piercing catamarans. A $2.5 \mathrm{~m}$ segmented model was designed to replicate the first longitudinal bending mode and damping ratio of the $112 \mathrm{~m}$ INCAT catamaran based on vibration data analysed on previous INCAT catamaran vessels. Model test work in head-seas has identified an extreme slam load case that is equivalent to a full scale slam load of 2150 tonnes weight $(21.09 \mathrm{MN})$, this being a substantial load estimated for a $112 \mathrm{~m}$ vessel with direct implications for the design bending load case and vessel fatigue life. RANS simulation at model scale predicted the peak slam load to occur at the same dimensionless encounter frequency as the model scale experimental work and predicted a peak slamming load slightly less than that observed experimentally. The maximum slam force location was predicted to be slightly forward than that measured during experiments whilst numerical pressure data had identified the location of the centre of pressure and peak pressure in the arch of the bow. Clearly the model test work has provided a basis for validating the numerical analysis and as computing processing speeds continue to increase there is further opportunity to use this capability for identifying the wave slamming impact loads on future wave-piercer catamaran designs.

Full scale work has shown that up to $3.5 \mathrm{MJ}$ of strain energy has been observed in the subsequent whipping vibrations while the model scale work extrapolated to a full scale estimate of up to 4.0 MJ. Due to the random conditions encountered at full scale as well as the associated uncertainty of the sea state it cannot be known if the full scale slam was as severe as that identified at model scale. While the peak strain energy generally correlated well, the estimated model scale slam impulses were greater than those observed at full scale, potentially due to a difference in the identification of the slam duration and hence limits of the force integration method applied.

Model scale experimental work has considered the full operational range of the vessel that would generally not be encountered in service due to voluntary speed reduction. Having considered equivalent full scale wave heights of up to $5.4 \mathrm{~m}$ it is considered that the results presented here include the most extreme slams that can occur. Although only regular seas have been considered, the resulting motions and loads are very representative of the conditions that may be encountered at full-scale during random sea conditions. During the model tests there was no complete immersion 
of the model centre bow which effectively provided forward buoyancy during large wave encounter. It thus appears that provided such vessels are designed to withstand the extreme loads identified, the $112 \mathrm{~m}$ INCAT wave piercer catamaran design is inherently seaworthy. It would be expected to sustain large wave loads in random seas in particular when subject to slamming, but seas trials of recent INCAT vessels have not resulted in structural damage.

Slamming of the wave piercer bow is a complicated unsteady hydrodynamic process as the bow enters a wave. Slamming occurs due to the rapid unsteady confluence of water displaced by the demi-hulls and center bow at the top of the arches in the hull cross section. In work described here we have used scale model testing as the basis for identifying the severity of slamming under these fully three dimensional, transient wave encounter conditions. CFD solutions are computationally very intensive and can be significantly affected by meshing. Further, the results obtained here are a more completely accurate indication of slamming severity than could be gained by simplified drop testing of two dimensional models of hull cross sections. Lastly, hydroelastic modelling is essential in identifying slam loadings owing to the generally similar values of the slam load duration and the period of structural whipping vibration.

\section{Acknowledgements}

The authors thank the Australian Research Council, the University of Tasmania Australian Maritime College, INCAT Tasmania and Revolution Design Pty Ltd for their support. Shinsuke Matsubara is also gratefully acknowledged for his contributions to designing the catamaran model as well as Walid Amin for his work on Finite Element Modelling.

\section{References}

Amin, W., 2009. Non-linear unsteady wave loads on large high-speed wave piercing catamarans. PhD thesis, University of Tasmania.

Amin, W., Davis, M.R., Holloway, D.S., Thomas, G.A., 2009. Slamming quasi-static analysis of an INCAT 98m high-speed wave-piercing catamaran. Proceedings of the International Conference on Innovation in High Speed Marine Vehicles, Fremantle, Australia. 
Davis, M.R., Watson, N.L., Holloway, D.S., 2004. Measurements and prediction of wave loads on a high speed catamaran fitted with active stern tabs. Marine Structures. 17 (7), 503-535.

Davis, M.R., Watson, N.L., Holloway, D.S., 2005. Measurements of response amplitude operators for an $86 \mathrm{~m}$ high speed catamaran. Journal of Ship Research. 49 (2),121-143.

Davis, M.R., Whelan, J.R., Thomas, G.A., 2007. Computational modeling of wet deck slam loads with reference to sea trial. 9th International Conference on Fast Sea Transportation, FAST ’07. 616-624.

Davis, M.R., Holloway, D.S., 2007. Passenger motions on equivalent monohulls, catamarans and trimarans. Australian Journal of Mechanical Engineering. 4 (2), 59-72.

Davis, M.R., Amin, W., Lavroff, J., Holloway, D.S., Thomas, G.A., Matsubara, S., Roberts, T.R., 2009a. Global and slam load model testing to support developing HSMV operations in severe sea conditions. 1st International Conference on Innovation in High Speed Marine Vessels. 1, 93-101.

Davis, M.R., Thomas, G.A., Holloway, D.S., Lavroff, J., Amin, W., Matsubara, S., Roberts, T.R., 2009b. Slamming and whipping of wave-piercing catamarans. 5th International Conference on Hydroelasticity in Marine Technology. 223-232.

Dessi, D., Mariani, R., Coppottelli, G., Rimondi, M., 2005. Experimental identification of wet bending modes with segmented model tests. 8th International Conference on Fast Sea Transportation, FAST ’05. 1-8.

Dessi, D., De Luca, M., Mariani, R., 2009. Correlation of model scale and full-scale analysis of the ship elastic response in waves. Hydroelasticity in Marine Technology University of Southampton.151-160.

Hermundstad, O.A., Aarsnes, J.V., Moan, T., 1995. Hydroelastic analysis of a flexible catamaran and comparison with experiments. 3rd International Conference on Fast Sea Transportation, FAST '95. 487-500.

Hermundstad, O.A., Aarsnes, J.V., Moan, T., 1999. Linear hydroelastic analysis of high-speed catamarans and monohulls. Journal of Ship Research. 43 (1), 48-63. 
Holloway, D.S., Lavroff, J., Davis, M.R., 2006. Global structural design of hydroelastic models. 5th International

Kapsenberg, G.K., Brizzolara, S., 1999. Hydro-elastic effects of bow flare slamming on a fast monohull. 5th International Conference on Fast Sea Transportation, FAST '99. 699-708.

Lavroff, J., Davis, M.R., Holloway, D.S., Thomas, G., 2007a. Experimental analysis of the wet flexural mode

Lavroff, J., Davis, M.R., Holloway, D.S., Thomas, G., 2007b. The whipping vibratory response of a hydroelastic segmented catamaran model. 9th International Conference on Fast Sea Transportation, FAST '07. 600-607.

Lavroff, J., 2009. The Slamming and Whipping Vibratory Response of a Hydroelastic Segmented Catamaran Model. $\mathrm{PhD}$ thesis University of Tasmania.

Lavroff, J., Davis, M.R., Holloway, D.S., Thomas, G., 2009. The vibratory response of high-speed catamarans to slamming investigated by hydroelastic segmented model experiments. RINA International Journal of Maritime Engineering. 151 (A4), 1-11.

Lavroff, J., Davis, M.R., Holloway, D.S., Thomas, G.A., 2013. Wave slamming loads on wave-piercer catamarans operating at high-speed determined by hydeo-elastic segmented model experiments. Marine Structures. 33, 120-142. Journal of Ship Research. 59 (3), 145-161. severe seas. Transactions of the Society of Naval Architects and Marine Engineers. 105, 427-453. 
McVicar, J.J., Lavroff, J., Davis, M.R., Davidson, G., 2014. Transient slam load estimation by RANSE simulation and by dynamic modelling of a hydroelastic segmented model. 30th Symposium on Naval Hydrodynamics, Hobart, Australia.

McVicar, J.J., Lavroff, J., Davis, M.R., Thomas, G., 2015. Slam excitation scales for a large wave piercing catamaran and the effect on structural response. 13th International Conference on Fast Sea Transportation, Washington DC, USA.

McVicar, J.J., Lavroff, J., Davis, M.R., Thomas, G., 2015. Effect of slam force duration on the vibratory response of a lightweight high-speed wave-piercing catamaran. Journal of Ship Research. 59 (2), 69-84.

Shahraki, J.R., 2014. The influence of hull form on the slamming behaviour of large high-speed catamarans. PhD thesis University of Tasmania.

Thomas, G., 2003. Wave slam response of large high-speed catamarans. PhD thesis University of Tasmania.

Thomas, G.A., Davis, M.R., Holloway, D.S., Roberts, T.R., 2003. The whipping vibration of large high speed catamarans. RINA International Journal of Maritime Engineering. 145, 289-304.

Thomas, G., Davis, M.R., Holloway, D.S., Roberts, T.R., 2008. The Vibratory Damping of Large High-Speed Catamarans. Marine Structures. 21, 1-22.

Thomas, G., Winkler, S., Davis, M.R., Holloway, D.S., Matsubara, S., Lavroff, J., French, B., 2010. Slam events of high-speed catamarans in irregular waves. Journal Marine Science and Technology. 16 (1), 8-21.

Whelan, J., 2004. Wetdeck Slamming of High-Speed Catamarans with a Centre Bow. PhD thesis University of Tasmania. 